\title{
14. The Precautionary Principle and the Dual-Use Dilemma
}

\author{
Steve Clarke
}

\section{Three precautionary principles}

The precautionary principle (PP) is a conceptual tool used to guide decisionmaking in the management of risk. ${ }^{1}$ It has been widely taken up in environmental law, and is now being applied in a variety of contexts, including the regulation of potentially dangerous technologies. It was first developed in Sweden and the former West Germany in the late $1960 s,{ }^{2}$ was explicitly used in West German environmental law by the $1980 \mathrm{~s}^{3}$ and has become increasingly influential in many countries since then, particularly in Europe. ${ }^{4}$ That the PP is usually referred to as the PP might seem to suggest that there is a canonical formulation of this principle. But this is not the case. There are at least 20 different versions of the $\mathrm{PP}^{5}$ and new ones appear on a regular basis. The fact that there are many different versions of an abstract principle is perhaps not surprising in and of itself. What is somewhat surprising is that these different principles do not appear to be variants of a more general principle. Instead, they are only loosely associated with one another. What they have in common is a shared history and the fact that they all advance precaution in some way. As we will see, they involve at least three very different approaches to the advancement of precaution, which can be understood in terms of their differing relationships with cost-benefit analysis (CBA) (also known as benefit-cost analysis).

Development of the PP was initially motivated by dissatisfaction with CBA, which was the dominant conceptual tool used in risk management until the rise of the PP, and which continues to be very widely applied. The application of

\footnotetext{
1 The PP is also sometimes understood, more broadly, as a set of guidelines for structuring the deliberative processes involved in risk management. See, for example, Rappert, B. and Moyes, R. 2010, 'Enhancing the protection of civilians from armed conflict: precautionary lessons', Medicine, Conflict and Survival, vol. 26, no. 1, pp. 24-47.

2 See Sunstein, C. 2005, Laws of Fear: Beyond the Precautionary Principle, Cambridge, Cambridge University Press, p. 16

3 Majone, G. 2002, 'What price safety? The precautionary principle and its policy implications', Journal of Common Market Studies, vol. 40, pp. 89-109.

4 The PP was referred to in 27 resolutions of the European Parliament between 1992 and 1999, is referred to in the 1992 Maastricht Treaty on the European Union, and appeared in a draft constitution for the European Union. See Sunstein, op. cit., p. 17.

5 See ibid., p. 18.
} 
CBA involves attempting to determine the probability of benefits occurring, and the probability of costs being incurred, as well as determining the relative sizes of the benefits and costs of a particular course of action and balancing these. This calculation is compared with the relative balance of costs and benefits for alternative courses of action from which the option with the best overall balance (adjusting for the probability of these occurring) is selected ${ }^{6}$ From the 1960s, environmental lawyers, policymakers and activists became increasingly dissatisfied with many of the decisions that were made with the use of CBA.

One source of dissatisfaction was that, in many actual applications, only potential costs that were established with 'full scientific certainty' were considered. A precautionary corrective to this tendency was the development of versions of the PP that were intended to guide the use of CBA so as to ensure that potential costs other than those established with 'full scientific certainty' were given due consideration. ${ }^{7}$ A good example of this form of the PP is Principle 15 of the Rio Declaration on Environment and Development: 'In order to protect the environment, the precautionary approach shall be widely applied by States according to their capabilities. Where there are threats of serious or irreversible damage, lack of full scientific certainty shall not be used as a reason for postponing cost-effective measures to prevent environmental degradation. ${ }^{8}$

A second complaint about decisions guided by CBA was that in some of these it was implicitly assumed that the onus of proof of the existence of a cost fell on critics of an activity. A precautionary response to this tendency was to supplement CBA with a second step specifying conditions under which the 'onus of proof' lay with proponents, rather than critics, of an activity. The wellknown Wingspread Statement is a good example of this sort of PP: 'Where an activity raises threats of harm to the environment or human health, precautionary measures should be taken even if some cause and effect relationships are not fully established scientifically. In this context the proponent of the activity, rather than the public, should bear the burden of proof. ${ }^{\prime 9}$

Neither insistence on full scientific certainty nor placement of the onus of proof on critics is intrinsic to $\mathrm{CBA}$; so the above versions of the PP supplement CBA,

\footnotetext{
6 This decision-making process is philosophically problematic in various ways, most obviously because benefits often appear to be incommensurable with risks. For a discussion of further philosophical problems with CBA, see Hansson, S. O. 2007, 'Philosophical problems in cost-benefit analysis', Economics and Philosophy, vol. 23, pp. 163-83. For a defence of CBA against various criticisms, see Schmidtz, D. 2001, 'A place for cost-benefit analysis', Philosophical Issues (A Supplement to Nous), vol. 11, pp. 148-71.

7 For more on the history of the development of this type of precautionary principle, see Magnus, D. 2008, 'Risk management versus the precautionary principle: agnotology as a strategy in the debate over genetically modified organisms', in R. N. Proctor and L. Schiebinger (eds), Agnotology: The Making and Unmaking of Ignorance, Stanford University Press, Stanford, Calif., pp. 250-65.

8 United Nations Environment Programme, 1992.

9 Wingspread Statement on the Precautionary Principle 1998, <www.gdrc.org/u-gov/precaution-3.html> (viewed 1 November 2010).
} 
rather than replacing it with an alternative. What have come to be known as strong versions of the PP (sPP), however, have been developed with the intention of replacing CBA, at least under certain circumstances, with an altogether different approach to risk management that does not involve weighing the costs and benefits of a particular policy and comparing these weightings with those of possible alternative policies. Instead, it involves an exclusive focus on the potential costs of a particular policy. An example of sPP is the Final Declaration of the First European 'Seas at Risk' Conference, 1994: 'If the "worst case scenario" for a certain activity is serious enough then even a small amount of doubt as to the safety of that activity is sufficient to stop it taking place.'10

Here we are instructed to focus our attention exclusively on costs and ignore the potential benefits of particular activities when making policy, no matter how significant these potential benefits might be.

We have focused on the above three examples of the PP because these are clear examples of different types of PP that are intended to advance precaution in particular ways. Not all versions of the PP are as clear as these. Indeed, some are couched in highly nebulous language that makes it hard to see what their creators are trying to achieve, beyond conveying enthusiasm for precaution. We will go on to examine an example of the PP, created especially for application in dual-use contexts, ${ }^{11}$ which suffers from this problem. Jordan and $\mathrm{O}^{\prime} \mathrm{Riordan}^{12}$ embrace the vagueness of (many versions of) the PP, which they see as a virtue that enables those who employ it to be more politically effective. This may be true if the PP is understood, as Jordan and $\mathrm{O}^{\prime}$ Riordan understand it, as an intellectual tool of protest movements; however, its vagueness becomes a vice when the PP is used to try to steer policy. ${ }^{13}$ Indeed, scholars who are concerned about effective precautionary regulation sometimes complain that while adoption of the PP changes conceptualisations of risks, it does not appear to have had a clear effect on regulatory practice. ${ }^{14}$

I have analysed the PP in terms of its different possible relationships to CBA. Some commentators, such as Sandin, ${ }^{15}$ might want to object to the direct

\footnotetext{
10 Cited in Sunstein, op. cit., p. 29.

11 Kuhlau, F., Hoglund, A. T., Evers, K. and Eriksson, S. 2011, 'A precautionary principle for dual use research in the life sciences', Bioethics, vol. 25, no. 1, pp. 1-8.

12 Jordan, A. and O'Riordan, T. 1999, 'The precautionary principle in contemporary environmental policy and politics', in C. Raffensperger and J. A. Tickner (eds), Protecting Public Health and the Environment: Implementing the Precautionary Principle, Island Press, Washington, DC, pp. 15-35.

13 Clarke, S. 2005, 'Future technologies, dystopic futures and the precautionary principle', Ethics and Information Technology, vol. 7, pp. 121-6.

14 O'Riordan, T. and Cameron, J. (eds) 1994, Interpreting the Precautionary Principle, Earthscan, London; and Eckley, N. and Selin, H. 2004, 'All talk, little action: precaution and European chemicals regulation', Journal of European Public Policy, vol. 11, pp. 78-105.

15 Sandin, P. 1999, 'Dimensions of the precautionary principle', Human and Ecological Risk Assessment, vol. 5, pp. 889-907.
} 
comparison of any form of the PP with CBA, taking the view that, while CBA has been developed to be applicable in circumstances where we need to make policy decisions under risk, the PP has been developed to address circumstances of uncertainty. The distinction between risk and uncertainty goes back to Knight. ${ }^{16}$ In his terminology, situations of risk are circumstances where the probabilities of possible outcomes can be specified, on the basis of reliable evidence, and situations of uncertainty are circumstances where the probability of possible outcomes cannot be specified, on the basis of reliable evidence. Flipping a normal coin creates an instance of risk without uncertainty as we know all the possible outcomes of a coin flip (heads and tails) and we are warranted in specifying particular probabilities for these outcomes. Speculation about the details of a possible afterlife is a case of uncertainty without risk. There are many possible accounts of the ways in which an afterlife might be experienced, but we appear to lack good grounds for assigning probabilities to any of them.

While coin flips are pure instances of risk and speculations about the afterlife seem to be pure instances of uncertainty, these are exceptional cases. The majority of real-world cases where decisions involving probabilities need to be made involve a mixture of risk and uncertainty. Consider a couple of real-world decisions: 1) an insurer who writes home insurance policies will try to price those policies on the basis of assessments of the risks to which particular houses are exposed. It is not possible, however, to anticipate all such risks and work out exactly how likely these are, so there is inevitably an element of uncertainty in such assessments. Exact probabilities can, of course, be assigned to possible outcomes, but such assignments will involve a degree of stipulation. 2) A patient who is contemplating an operation will want to know what the risks involved are and the surgeon who is set to conduct the operation will generally try to transmit this information to the best of her ability. But while it is possible to anticipate many of the risks involved in a complex operation, estimates of how likely these are to occur in particular contexts will inevitably involve a degree of speculation. In many real-world circumstances, we attempt to turn uncertainties into risks, however, this typically involves some speculation and so an element of uncertainty remains. ${ }^{17}$ Most real-world circumstances involve a mix of risk and uncertainty and the PP and CBA can both be applied to these. So it is appropriate to make direct comparisons of CBA and the PP in dealing with most real-world cases.

16 Knight, F. 1921, Risk, Uncertainty, and Profit, Hart, Schaffner \& Marx, Boston.

17 Knight's view of risk is based on the (I think plausible) presupposition that we try to assign objective probabilities to the world, and that when we are unable to do so, we are left with uncertainties: LeRoy, S. F. and Singell, L. D. 1987, 'Knight on risk and uncertainty', The Journal of Political Economy, vol. 95, pp. 394-406. Some commentators, such as Friedman, who take the view that we only ever assign subjective probabilities to the world, hold that we never need to have recourse to the Knightian concept of uncertainty at all. Friedman, M. 1962, Price Theory: A Provisional Text, Aldine, Chicago. 


\section{Precaution, paradox and bias}

Strong versions of the PP (sPP) have attracted much controversy and have been subjected to an apparently devastating form of criticism, which is that they typically lead to contradictory policy recommendations, if applied consistently, and are therefore paralysing. ${ }^{18}$ This is because viable alternatives to a policy typically have risks associated with them and if all of these are given due consideration under sPP then policy paralysis will result. Consider, for example, the application of sPP to the possible development of nuclear power plants, intended to address an impending shortage of energy in a particular country. Clearly there are risks associated with building and running nuclear power plants, so an application of sPP would lead to the recommendation that we do not develop nuclear power plants. But what will happen if we fail to develop nuclear power in this context? Viable alternatives seem also to involve risks. If we develop new sources of power that are based on fossil fuels then we increase the chance and severity of climate change. So sPP precludes the development of new fossil fuel-based power sources. Another alternative is not to provide additional power but to try to convince people to use less energy. But this alternative involves the risk of social instability, so sPP precludes the policy of not developing new sources of power. If the three options considered above are our only viable alternatives then the consistent application of sPP necessarily provides incoherent policy recommendations, precluding all viable courses of action, and also precluding inaction.

One way that advocates of sPP have attempted to avoid paralysing paradoxical outcomes is by insisting that only risks over a certain threshold of significance (understood in terms of probability of occurrence and/or seriousness of costs involved) be considered in formulations of the PP. ${ }^{19}$ Indeed our exemplar of sPP, the 'Final Declaration', mentions risks being 'serious enough' to warrant consideration (although it does not specify how likely it is that these will be realised), so it might be supposed that it is an instance of sPP that can avoid paradoxical outcomes. The advocate of this strategy to defend sPP from the change of paradox needs to make a choice about where to set the levels of significance and/or likelihood of occurrence of risks. If these are set too high then sPP will not be applicable to many of the risks that advocates of precaution have wished to apply it to. On the other hand, if they are set too low then the problem of paradox won't be avoided and sPP will continue to issue contradictory advice. ${ }^{20}$ In effect this is a 'Goldilocks strategy': it might work

18 Manson, N. A. 2002, 'Formulating the precautionary principle', Environmental Ethics, vol. 24, pp. 26374; and Sunstein, op. cit.

19 Sandin, P., Peterson, M., Hannson, S. O., Rudén, C. and Juthe, A. 2002, 'Five charges against the precautionary principle', Journal of Risk Research, vol. 5, pp. 287-99.

20 See Clarke, op. cit., p. 126. 
if we know in advance where to set levels of significance, but because we are dealing with the management of uncertain outcomes we usually don't have any reliable way of knowing where to set such thresholds, so there is not usually any reason to be confident that our strategy has succeeded. There have been other attempts to evade or resolve the paradox of $\mathrm{sP}^{21}$ but they do not appear to be successful either. ${ }^{22}$

If sPP leads to incoherent policy recommendations and causes policy paralysis then it seems odd that this is not often noticed by those who attempt to apply sPP, such as those who attempt to apply the 'Final Declaration'. The reason this is not often noticed is that when SPP is applied it is usually applied selectively. We are able to apply sPP when we focus on one possible policy outcome and fail to consider alternatives; and it seems that we have a propensity to do this. This propensity is encouraged by the structure of the PP. Whereas CBA involves an explicit consideration of alternative policies, most versions of the PP are designed to be applied to one policy option at a time, and do not involve explicit comparison with alternatives. According to Sunstein, ${ }^{23}$ there is also a deeper reason we tend to consider risks selectively when applying the $\mathrm{PP}$, which is that we are hostage to a variety of significant cognitive biases that have the effect of blinding us to the fact that we are typically faced with risks however we decide to act (and even if we don't act). Sunstein mentions various sources of cognitive bias that have this effect including probability neglect, a belief in the benevolence of nature, loss aversion and systems neglect; ${ }^{24}$ however, the factor he considers the most significant in encouraging a selective approach towards risk is the widespread use of the availability heuristic. ${ }^{25}$

The availability heuristic is a rule of thumb that people intuitively use to estimate the magnitude of particular risks. If I am asked how likely an earthquake, a flood or a bushfire is in Oxford, I will tend to make intuitive assessments of the likelihood of these events by seeing how readily I can bring to mind episodes in which such events have taken place in Oxford and will adjust my estimates in accordance with the 'availability' to me of instances of such events. Availability

\footnotetext{
21 Gardiner, S. M. 2006, 'A core precautionary principle', Journal of Political Philosophy, vol. 14, pp. 33-60; and Weckert, J. and Moor, J. 2006, 'The precautionary principle in nanotechnology', International Journal of Applied Philosophy, vol. 20, pp. 191-204.

22 Clarke, S. 2009, 'New technologies, common sense and the paradoxical precautionary principle', in P. Sollie and M. Duwell (eds), Evaluating New Technologies: Methodological Problems for the Ethical Assessment of Technological Developments, Springer, Dordrecht, pp. 159-73.

23 Sunstein, op. cit.

24 Ibid., p. 37.

25 See ibid., p. 5. For more on the availability heuristic, see Tversky, A. and Kahneman, D. 1982, 'Judgment under uncertainty: heuristics and biases', in D. Kahneman, P. Slovic and A. Tversky (eds), Judgment under Uncertainty: Heuristics and Biases, Cambridge University Press, Cambridge, pp. 3-21; and Kahneman, D. and Frederick, S. 2002, 'Representativeness revisited: attribute substitution in intuitive judgment', in T. Gilovich, D. Griffin and D. Kahneman (eds), Heuristics and Biases: The Psychology of Intuitive Judgment, Cambridge University Press, Cambridge, pp. 49-81.
} 
is influenced by both familiarity and salience. ${ }^{26}$ The more familiar I am with a class of events, all things being equal, the greater will be my intuitive assessment of its likelihood. If a class of events is particularly salient to me-if, say, I have personal experience of a flood or have just watched a documentary about the danger of flooding in the Thames Valley, where Oxford is located - then that will also increase my intuitive estimate of the likelihood of flooding in the area. ${ }^{27}$

When particular risks are highly available to us they tend to 'crowd out' other risks that we would otherwise be inclined to consider. After the events of 11 September 2001, ordinary estimates of the dangers associated with air travel rose dramatically, particularly in America, and this led many people to alter their travel plans and drive or take a train rather than fly. It seems that such decisions, made at that time, were a response to the high availability of the dangers of air travel, which crowded out consideration of the risks involved with other forms of transport. But the risks of alternative travel choices were significant. It is estimated than an extra 350 road fatalities occurred in America in the final three months of 2001 as a result of people avoiding air travel in the aftermath of the events of 11 September. This is a higher number of deaths than the number of deaths of passengers and crew in all four of the crashed flights of 11 September combined (266 deaths). ${ }^{28}$

\section{Dual use and lessons from debates about the precautionary principle}

A dual-use dilemma arises when a piece of research-typically in the life sciences - has potential benefits as well as the potential to cause harm. ${ }^{29}$ If we go ahead and conduct this research then we may enjoy the benefits that might result from it, but only if we are willing to bear the risk of potential harms. If we do not conduct such research then potential harms are avoided but benefits are also forgone. How are we to decide what to do? The most obvious way to attempt to make such decisions is by applying CBA, under which we attempt to weigh the potential benefits of use of the potential piece of research in question against the potential harms. It has recently been suggested, however, that the PP

\footnotetext{
26 See Sunstein, op. cit., p. 37.

27 The passage of time will tend to decrease both familiarity and salience, and thereby lead to a decrease in intuitive estimates of likelihood.

28 Gigerenzer, G. 2004, 'Dread risk, September 11 and fatal traffic accidents', Psychological Science, vol. 15, pp. 286-7.

29 Miller, S. and Selgelid, M. 2007, 'Ethical and philosophical consideration of the dual-use dilemma in the biological sciences', Science and Engineering Ethics, vol. 13, p. 524.
} 
could be usefully applied in dual-use contexts. ${ }^{30}$ Even more recently, a specific formulation of the PP for application in 'dual-use life-science research' has been developed, which we will go on to consider.

If a PP is to be applied to dual-use dilemmas then I would urge those who are attempting to apply it to be as clear as they can about what role the PP is supposed to play in the resolution of dual-use dilemmas. As we have seen, it might be expected to play (at least) three very different roles in decisionmaking. First, the PP might be used to ensure that some harms, which might not be properly considered, are properly considered in applications of CBA in dualuse contexts. Second, it might be invoked in an attempt to specify where the 'onus of proof' lies in respect of either the significance of particular harms or the viability of particular remedies for those harms. Third, it might be invoked as an alternative to CBA. There is no one way to be cautious, and it is important that we try to be clear about how we intend to be cautious, if we are to do so in dualuse contexts. It is also important that we explain why we need to be cautious in this or that particular way. What is the particular failing of current approaches to dual-use dilemmas that the PP is supposed to help address; and are there any other possible responses to this problem that we might also consider?

As we have seen, one of the key problems with some versions of the PP (sPP) is that application of these depends on us adopting a selective approach to risk. We can adopt a selective approach to risk and be oblivious to the fact that we are doing so because of widespread cognitive bias that affects ordinary assessments of risk. We should ask ourselves whether framing a problem as a dual-use dilemma makes us more or less susceptible to adopting selective attitudes towards risk. We should also ask ourselves if applying sPP (or other versions of the PP) adds to such problems or reduces these. When we are considering whether to develop a new drug, framing our choice as a dual-use dilemma encourages us to focus our attention on a comparison of the consequences of going ahead and developing the drug, which will involve potential benefits as well as potential costs, with the consequences of not developing the drug. We may be in a position, however, to develop a variety of different drugs that provide overlapping benefits and involve overlapping risks. Rather than considering choices about which of these to develop and which not to develop as a series of isolated dilemmas, it may be more sensible to try to make a comparison of the overall benefits and costs of each, before deciding which options to pursue.

Framing a problem as a dual-use dilemma may well increase our propensity to adopt selective approaches to risk. When we frame a potential development as a dual-use dilemma (or any other sort of dilemma), we are encouraging a focus on

30 See Rappert, B. 2008, 'The benefits, risks and threats of biotechnology', Science and Public Policy, vol. 35 , p. 40 . 
a choice between exactly two alternatives; however, as is the case with the above example, there may be contexts in which we may be able to make comparative choices that are more complicated than simple dilemmas, and such possibilities may be obscured from us by framing our choice as a dilemma. ${ }^{31}$

Framing a problem as a dual-use dilemma encourages us to consider a choice between two alternatives in isolation from other possible choices. And at least some versions of the PP (sPP) can only be applied if we make a decision about risks in isolation from consideration of alternatives. Other versions of the PP, including the Wingspread Statement and the Rio declaration, are also structured around consideration of the risks that are associated with a particular activity and do not encourage us to consider risks involved with alternatives to that activity. The concern here is that if the PP is applied to the dual-use dilemma then the tendency of both of these conceptual structures to focus our attention on a particular policy option, to the exclusion of consideration of other options, may reinforce one another. So we have a reason to be especially wary about applying PP when that is combined with the framing of options as dilemmas.

\section{A suggested precautionary principle for dual- use contexts}

Kuhlau et al. suggest the following formulation of the PP for application in 'dualuse life-science research': 'When and where serious and credible concern exists that legitimately intended biological material, technology or knowledge in the life sciences pose threats of harm to human health and security, the scientific community is obliged to develop, implement and adhere to precautious measures to meet the concern.' ${ }^{32}$

This is a very vague formulation of the PP and a key problem here is to understand what sort of PP Kuhlau et al. ${ }^{33}$ intend us to apply. The most straightforward reading is that they are pointing out that when the risk of serious costs is present, serious remedies will be required if these are to be addressed. The problem with this suggestion is that it is hard to see what work is being done by the PP, as an implication of ordinary CBA is that when the risk of serious costs is at stake serious remedies will be required if these are to be addressed.

\footnotetext{
31 This problem may become resolved as language evolves. The word 'dilemma' is sometimes used these days in a way that is meant to be inclusive of tri-lemmas, quadri-lemmas, and so on. If this usage becomes sufficiently common then framing a decision as a dilemma will no longer encourage a forced choice between exactly two alternatives.

32 Kuhlau et al., op. cit., p. 6.

33 Ibid., pp. 1-8.
} 
But perhaps Kuhlau et al. mean to offer the scientific community a reminder that there are threats to human health and security that can arise from lifescience research and they are insisting that the scientific community considers these when deciding whether or not to conduct particular research that may lead to harms. On this second reading, their version of the PP is supposed to function like the Rio declaration and is designed to ensure that, when costs and benefits are weighed up, the potential costs of certain risks are not excluded from consideration. If this is the sort of reading that is intended then it would be useful to know what motivates Kuhlau et al. to suppose that there is a danger of these concerns not being considered, when consideration of them is expected under the application of ordinary CBA. The Rio declaration was developed in response to a history of significant risks being ignored on the (fallacious) grounds that if these had not been established with 'full scientific certainty' then they should not be considered at all. But is there a reason to think that threats to human health and security are liable to be ignored by the scientific community $?^{34}$ If there is no particular reason to believe that this may happen then it seems that Kuhlau et al. ${ }^{35}$ have created a gratuitous version of the PP that performs no needed function.

On a third possible reading, Kuhlau et al. intend a strong version of the PP. Their wording is ambiguous, but they may intend that the scientific community only allows research in the life sciences to go ahead once all concerns regarding possible threats to human health and security have been met, no matter how potentially beneficial such research may be. If they do intend this strong reading then it would be useful to know how the following two questions can be answered. First, it would be useful to know why they think we should accept this strong precautionary approach. If the benefits of some piece of research are judged to outweigh the risks, and if all significant possible costs and benefits have been considered, why shouldn't we accept the risks of conducting such research, in order to try to reap potential benefits? Second, we need to be told how the problem of paradox is to be avoided. ${ }^{36}$ In many situations there will be risks involved in not conducting research in the life sciences. If we do not take the risks involved in developing new vaccines for currently lethal diseases, for example, we implicitly accept the risks of people continuing to die as a result of

\footnotetext{
34 Tom Douglas suggests that there is a tradition in the scientific community of denying that scientists should be held responsible for the ways in which scientific knowledge is employed and that Kuhlau et al. may be intending to issue a special reminder to scientists, as a way of trying to overcome the influence of this tradition. Also Selgelid suggests that biological scientists and bioethicists have a history of ignoring the dual-use potential of genetics. See Selgelid, M. 2010, 'Ethics engagement of the dual-use dilemma: progress and potential', in B. Rappert (ed.), Education and Ethics in the Life Sciences, ANU E Press, Canberra, pp. 23-34. 35 Kuhlau et al., op. cit.

36 Kuhlau et al. consider some objections to the PP, including the objections that it stifles scientific development, it lacks practical applicability and that it is poorly defined and vague. They do not consider the applicability of these charges to specific versions of the PP and they do not consider the charge that (strong versions of) the PP leads to contradictory policy recommendations.
} 
these diseases. It looks like Kuhlau et al.'s version of the PP (on a strong reading) is susceptible to the problem of there being 'risks on all sides' and so it looks like it leads to paradoxical recommendations, if applied consistently. ${ }^{37}$

The PP can be useful in particular contexts when it has specific uses. There may be particularly good uses for a PP developed to suit dual-use contexts. Unfortunately, Kuhlau et al. ${ }^{38}$ are not clear about the uses to which they wish to put their version of the PP and it looks like their version is not designed to suit any specific use. If others wish to develop new versions of the PP for dualuse contexts then I would urge that they use precise language and specify what their version of the PP is intended to achieve.

37 Thanks to Linsey McGoey, Brian Rappert and Tom Douglas for some very helpful comments on an earlier version of this chapter.

38 Kuhlau et al., op. cit. 